\title{
PAST, PRESENT, FUTURE: COEXISTENCE, SEPARATION, RECONCILIATION
}

Over the centuries, ethnic Sudeten Germans and ethnic Czechs in Bohemia and Moravia have been relatively disinterested neighbors, separated by geography, language and culture. At times, though, they have experienced years of peace and creative interaction as well as moments of overt hostility. The record is mixed, influenced by decisions taken by manipulative politicians in distant capitals. Like other ethnic groups inhabiting ethnic frontiers, their acceptance or rejection of each other depended as much on external factors as it did on the dynamics of local ones.

The twentieth century proved especially disruptive and divisive; militant nationalism and exclusivist ethnopolitics undermined centuries of fragile but relatively civilized levels of mutual tolerance. The fall of the Habsburg Empire and the formation of Czechoslovakia shifted the balance of relationships from one generally favoring German speakers to one advantageous to the Czech majority. The rise of National Socialist Germany introduced virulent ethno-racism and all its lethal consequences into the region: ethno-separatism with the Third Reich's annexation of the Sudeten area; the dismantling of Czechoslovakia and the reduction of the Czechs to a stateless, sub-racial population, and, after the Second World War, the mass expulsion of nearly three million ethnic Germans from the former Sudetenland.

This final act of ethnic cleansing marked the tragic closing of a long chapter of ethnic German-Czech co-existence inside the same borders. Separated by an international border since 1945, the two groups have lived on opposite sides of the Iron Curtain. Their contact was minimal and, one might have concluded, their memories of one another would fade quickly due to an all-absorbing present for the uprooted German exiles and an increased ideology-driven focus on the future on the part of Communist-dominated Czechs. But history is full of surprises and ironic moments.

With the demise of communist regimes in the east and the merging of East Germany into West Germany, old recollections have resurfaced. Most recently, ageing former Sudeten Germans and their offspring have raised the issue of compensation publicly. Reluctantly, the Bundestag has agreed to debate the question, thereby, politicizing it. In turn, prominent voices in the Czech Republic have joined the dispute, raising not only objections but making counter-demands for compensation for losses incurred during the German occupation 50 years ago.

Unfortunately, selected historic memories lie deep, providing fodder for contemporary disputes: Bosnia is a case in point. It is helpful, therefore, to provide a sober examination of the history of ethnic-German/Czech relations before the onset of the 
crisis of the Second World War. Readers of this Special Topic issue will not only be enlightened, but may adduce several lessons applicable to the contemporary scene, as ethnic confrontations proliferate and conflicts deepen, despite decades of proximity in relative tranquillity. Nevertheless, despite all scholarly effort, we are still a long way from understanding fully the dynamics that drive ethnic groups together or apart, from the ideal of a tolerant, pluralistic, ethnic civil society to the nightmare of ethnic killing fields.

HRH 